\title{
Molecular Characterization and Transcription Analysis of P-Glycoprotein Gene from the Salmon Louse Caligus rogercresseyi
}

Valentina Valenzuela-Muñoz, Gustavo Nuñez-Acuña and Cristian Gallardo-Escárate*

Laboratory of Biotechnology and Aquatic Genomics, Interdisciplinary Center for Aquaculture Research (INCAR), University of Concepción, P. O. Box 160-C, Chile

\begin{abstract}
Despite the efforts to manage the infestation Caligus rogercresseyi on salmon species, overuse of chemical antiparasites such as avermectins, organophosphates and pyrethroids have increasingly generated drug resistance, impacting on the efficacy of salmon lice control measures. So far, previous reports have evidenced that the ATPbinding cassette transporter P-glycoprotein (Pgp) is a candidate gene implicated in the response of salmon lice to neurotoxins. However, transcription patterns of Pgp in presence of pyrethroids and the expression pattern during the ontogenetic stages are still not complete elucidated. Herein, this study characterizes the Pgp mRNA from $C$. rogercresseyi $(\mathrm{Cr}-\mathrm{Pgp})$ and evaluates the transcription expression in during its lifecycle, and also in adults exposed to the antiparasitic drug deltamethrin (AlphaMax ${ }^{\circledR}$ ). The molecular characterization of $\mathrm{Cr}-\mathrm{Pgp}$ showed a complete sequence of 4,730 bp, containing a 5'UTR of $56 \mathrm{bp}$, 3'UTR of $833 \mathrm{bp}$, and open reading frame (ORF) of 3,840 bp encoding for 1,280 amino acids. Interestingly, eleven SNPs were identified, being two of them nonsynonymous polymorphisms. Cr-Pgp transcription expression was evaluated in conjunction with cytochrome P450 due its wellestablished role as key molecule in drug detoxifications. Herein, Cr-Pgp transcription was mainly associated to adult females than males exposed to deltamethrin, which was also linked with cytochrome P450 expression in adult females at $2 \mathrm{ppb}$ of deltamethrin. This study suggests that Cr-Pgp gene is involved in pyrethroid detoxification and evidences specific expression patterns related to developmental stages, as well as provides novel SNPs that could be associated with resistance/susceptibility to delousing drugs.
\end{abstract}

Keywords: Caligus rogercresseyi; P-glycoprotein; qPCR; Pyrethroid; P450 enzyme; SNP

\section{Introduction}

One of the most important defense mechanisms of ectoparasites against chemotherapeutic or xenobiotic agents is related with the ATPbinding cassette $(\mathrm{ABC})$ transporter family [1] he $\mathrm{ABC}$ transporters have been associated to multidrugs resistance (MDR) in different organisms. $A B C$ proteins are able to recognize different chemical substrates and to control their transport on a cellular level [2]. Through this, the $\mathrm{ABC}$ proteins have a pivotal role in blocking high concentrations neurotoxins, which intend to enter into the nervous system of parasitic invertebrates [3,4]. Within this family of proteins are the multidrug resistance-associated protein, the half-transporters, and the P-glycoprotein (Pgp). Pgp is a highly conserved membranebound protein in eukaryotes and prokaryotes, and it functions as an ATP-dependent efflux pump, reducing the concentration of drugs in the cells and conferring resistance [5-7]. In mammals, Pgp has been reported as one of the principal barriers against the entrance of drugs from the blood stream into the nervous system [8].

Caligus rogercresseyi [9] constitutes the main cause of economical losses in farmed salmon Chilean industry. Infection by the salmon louse does not generally cause host death, but its interaction with the salmon causes a high level of stress which depresses the immune system and increases susceptibility to bacterial and viral pathogens $[10,11]$. In order to control the prevalence of C. rogercresseyi, xenobiotics like pyrethroids [11], organophosphates [12], and avermectins [13] have been used. The overuse of these chemical agents has been shown to diminish their efficiency in treating parasite infestations due to resistance [14-16]. The time required by the parasite to acquire resistance depends on various factors, among which are environmental conditions and the concentration and frequency of the treatment [12,17-19]. Numerous studies have shown behavioral differences of the salmon louse when it is exposed to parasiticides depending on its developmental [20-22]. Avermectins used for the salmon louse control, such as emamectin benzoate (EMB), have been shown to be effective during the development stages of copepods [23]. Herein, Pgp has been observed to be the main defense of the salmon louse against xenobiotics, particularly to EMB, which joins to the gamma-aminobutryric acid (GABA) receptors, causing paralysis [24]. The authors Heumann et al. [17] identified Pgp in Lepeophtheirus salmonis [18] that were overexpressed in resistant strain after $24 \mathrm{~h}$ of exposure to $\mathrm{EMB}$, suggesting their participation in the response to the antiparasite. Other xenobiotic used for sea lice control is the pyrethroid named deltamethrin $\left(\right.$ Alphamax $\left.^{\circledR}\right)$. Deltamethrin is applied by topical treatments and interact with sodium channel depolarized the nerve ending [26]. Similarly, it has been observed that the family of cytochrome P450 enzymes participates in pyrethroid detoxification process in insects [27-29].

In Chile, the most widely used xenobiotic for the salmon lice control is deltamethrin [30]. However, there are no studies addressed to evaluate the transcription expression of $P g p$ from salmon louse exposed to deltamethrin. Moreover, studies are limited in regards to the functions that detoxification genes like Pgp have during the development of salmon lice, and it is only possible to find

*Corresponding author: Dr. Cristian Gallardo-Escárate, Laboratory of Biotechnology and Aquatic Genomics, Interdisciplinary Center for Aquaculture Research (INCAR), University of Concepción, P. O. Box 160-C, Chile, Tel: 56-412661008; E-mail: crisgallardo@udec.cl

Received April 24, 2014; Accepted May 28, 2014; Published June 18, 2014

Citation: Valenzuela-Muñoz V, Nuñez-Acuña G, Gallardo-Escárate C (2014) Molecular Characterization and Transcription Analysis of P-Glycoprotein Gene from the Salmon Louse Caligus rogercresseyi. J Aquac Res Development 5: 236 doi:10.4172/2155-9546.1000236

Copyright: (C) 2014 Valenzuela-Muñoz V, et al. This is an open-access article distributed under the terms of the Creative Commons Attribution License, which permits unrestricted use, distribution, and reproduction in any medium, provided the original author and source are credited. 
comparative studies on the effects that EMB has on expression levels in adult copepods. Given this, the aims of the present study were to perform a molecular characterization of the P-glycoprotein in Caligus rogercresseyi, evaluate their expression in adults treated with deltamethrin and assay its expression on a transcriptomic level during larval and adult stages.

\section{Materials and Methods}

\section{Samples}

Samples from the copepodid and chalimus stages and of adult male and female sea lice were collected from a commercial farm located in region X in Chile ( $\left.41^{\circ} 40^{\prime} 48.5^{\prime \prime} \mathrm{S} ; 7^{\circ} 02^{\prime} 31.34{ }^{\prime \prime} \mathrm{O}{ }^{\prime \prime}\right)$. The permissions for the sea lice collections were authorized by Marine Harvest S.A, Ruta 226, Km. 8, Camino El Tepual, Puerto Montt, Chile. The specimens were used to characterize the Pgp mRNA. A pool of each stage was fixed in RNAlater ${ }^{\circledR}$ RNA Stabilization Reagent (Ambion, USA) and stored at $-80^{\circ} \mathrm{C}$ for subsequent RNA extraction.

\section{Bioassay}

Formulations of deltamethrin were made using "AlphaMax ${ }^{\mathbb{B}}$ " (10 mg deltamethrin/mL) diluted with seawater to six concentrations $(0,1,2,3 \mathrm{ppb})$. A stock solution of $10 \mathrm{ppm}$ was prepared for each bioassay by diluting $1 \mathrm{ml}$ AlphaMax in $999 \mathrm{ml}$ seawater. The other concentrations were made by serial dilutions. Thirty adults (fifteen females and five males) of sea louse were exposed to each concentration of the deltamethrin formulation in petri plate containing $50 \mathrm{ml}$ of seawater (three biological replicates were also evaluated). The exposure period was $40 \mathrm{~min}$ according to the recommended treatment time for AlphaMax. During the exposure, organisms were maintained at $12^{\circ} \mathrm{C}$. After $24 \mathrm{~h}$ the sea louse were fixed in RNAlater ${ }^{\circledR}$ RNA Stabilization Reagent (Ambion, USA) and stored at $-80^{\circ} \mathrm{C}$ for subsequent RNA extraction.

\section{P-glycoprotein gene isolation}

A partial sequence of the $P g p$ gene was identified from a $C$. rogercresseyi EST-database from Illumina MiSeq library generated for C. rogercresseyi in the Laboratory of Biotechnology and Aquatic Genomics, Interdisciplinary Center for Aquaculture Research (INCAR), University of Concepción. The sequence was used as a template for primer design with the Primer3 tool [30] (Table 1) included in the Geneious Pro software [31]. For gene amplification, total RNA was isolated using the TRI reagent (Invitrogen, Carlsbad,

\begin{tabular}{|l|l|}
\hline Primername & Primer Sequence \\
\hline Cr-Pgp_F & ACACCTTTCCTGGATGGAGTCACTC \\
\hline Cr-Pgp_R & CTTGCGTTCCATTTGTCCAT \\
\hline Cr-Pgp_Race5_R1 & AATGAGACCAATGATGGCCG \\
\hline Cr-Pgp_Race5_R2 & AAAGCGAGTGACTCCATCCA \\
\hline Cr-Pgp_Race3_F1 & TTGAATCAAGGACGAGTGGC \\
\hline Cr-Pgp_Race3_F2 & AAGTCACGACTCACTCCTCT \\
\hline Cr_P-gp_qF & AATCTTCCGAGGTGTCCTCA \\
\hline Cr_P-gp_qR & ACAGAGTTCTCGGTCGTCTA \\
\hline Cr_P450_qF & CACCAGGATTTTCAGCTCCA \\
\hline Cr_P450_qR & TACTTCCCGGAACCCAATGA \\
\hline Cr_1266_F & TGATGGTGGATGATGTGGAC \\
\hline Cr_1266_R & AAAACTGGCTCTTGGCCTAC \\
\hline Cr_1353_F & TCGGGATAATATCTGCGTCG \\
\hline Cr_1353_R & AAAATCGTACGCATTCGCAG \\
\hline & Table 1: Sequences of primers used in this study. \\
\hline
\end{tabular}

CA, USA) protocol. The purity was determined (ratio A260/A280) with a Nanodrop ND1000 spectrophotometer (Thermo Fisher Scientific, Copenhagen, USA), and the integrity was determined by agarose gel under denaturant conditions. From $200 \mathrm{ng} / \mu \mathrm{l}$ of total RNA, cDNA was synthetized using the RevertAid H Minus First Strand cDNA Synthesis Kit (Thermo Scientific, Glen Burnie, Maryland, USA). PCR analysis was performed using $1 \mu \mathrm{l}$ of cDNA, $10 \mu \mathrm{M}$ of each primer (Table 1), $1.5 \mathrm{mM} \mathrm{MgCl}$, and $0.06 \mathrm{U}$ taq DNA polymerase (Thermo Scientific, Maryland, USA). PCR was performed in 35 cycles of denaturation at $94^{\circ} \mathrm{C}$ for $30 \mathrm{~s}$, annealing at $60^{\circ} \mathrm{C}$ for $30 \mathrm{~s}$, and extension at $72^{\circ} \mathrm{C}$ for 45 s. The PCR product was observed by electrophoresis on $1 \%$ agarose gel and sequenced in the ABI 3730xl sequencer (Applied Biosystems, CA, USA). The sequence was analyzed using the Geneious 5.1.6 software [31]. The resulting partial sequence, termed Cr-Pgp, was used for designing specific new primers (Table 1 ) for the amplification of the 3 ' and 5 ' UTR ends through the SMARTer ${ }^{\text {TM }}$ RACE cDNA Amplification Kit (Clontech) according to the manufacturer's instructions. The fragments obtained for the 5' and 3' UTR ends were cloned in the TOPO TA Cloning Kit (Invitrogen ${ }^{\mathrm{TM}}$, Life Technologies, Carlsbad, CA, USA) and transformed into E. coli JM109 electrocompetent bacteria in $\mathrm{LB} / \mathrm{amp} / \mathrm{IPTG} / \mathrm{Xgal}$ plates overnight at $37^{\circ} \mathrm{C}$. The positive clones were selected and purified to obtain plasmid by using the E.Z.N.A ${ }^{\circledR}$ Plasmid DNA Mini Kit II (Omega Bio-tek, Doraville, GA, USA). The plasmids obtained were sequenced in both directions, and their sequences were then assembled using the software Geneious 5.1.3. [31].

\section{Amino acid sequence analyses}

Protein alignments were conducted using MUSCLE, and phylogenetic trees were constructed using the neighbor-joining method with 1,000 bootstrap repetitions. Both analyses were carried out in Geneious 5.1.6 [31]. For identifying the conserved domains and active sites, the PROSITE [32] and SMART [33] platforms were used.

\section{SNPs mining and validation}

Using the assembly obtained for the Pgp sequence, SNPs mining was performed using the Genomics Workbench 5.0.1 software (CLC bio, Denmark). The parameters used were as follows: window length $=11$, maximum gap and mismatch count $=2$, minimum average quality of surrounding bases $=15$, minimum quality of central base $=20$, maximum coverage $=100$, minimum coverage $=8$, minimum variant frequency $(\%)=35.0$, and maximum expected variations (ploidy) $=2$.

For SNPs validation, high resolution melting analysis (HRMA) was performed using primers designed with the Primer3 tool [30] (Table 1) included in the Geneious Pro software [31]. Total DNA was isolated using the E.Z.N.A DNA extraction kit (Omega) from 20 adult salmon lice (10 females and 10 males). The PCR was carried out in $10 \mu \mathrm{l}$ reaction with 13 ng of template DNA using the Fast EvaGreen ${ }^{\circledR}$ qPCR Master Mix (Biotum). For HRMA, thermal cycling was performed with an ECO Real Time PCR System (Ilumina Inc, USA) as follows: 2 min for enzyme activation, 40 cycles at $95^{\circ} \mathrm{C}$ for $5 \mathrm{~s}, 56^{\circ} \mathrm{C}$ for $5 \mathrm{~s}$, and $60^{\circ} \mathrm{C}$ for $25 \mathrm{~s}$. HRMA data were collected between 60 and $95^{\circ} \mathrm{C}$ with a temperature interval of $0.3 \%$. Genotyping was analyzed for the presence of a discrete melting curve using the software EcoReal Time System (Illumina Inc. USA).

\section{Expression profiles of $\mathrm{Cr}-\mathrm{PgP}$}

Transcripts levels were evaluated for the copepodid and chalimus stages and for adult females and males of $C$. rogercresseyi. On other hand, an expression level of $C r-P g p$ in sea lice exposed to deltamethrin were evaluated and compared with $\mathrm{P} 450$ gene expression. The primers 
Citation: Valenzuela-Muñoz V, Nuñez-Acuña G, Gallardo-Escárate C (2014) Molecular Characterization and Transcription Analysis of $P$-Glycoprotein Gene from the Salmon Louse Caligus rogercresseyi. J Aquac Res Development 5: 236 doi:10.4172/2155-9546.1000236

Page 3 of 7

for qPCR reactions were designed from the sequences obtained from $\mathrm{Cr}$ $P g p$ and from partial sequence of $\mathrm{Cr}$-P450 identified in Illumina MiSeq library for C. rogercresseyi (Table 1). The qPCR runs were performed with StepOnePlus ${ }^{\mathrm{TM}}$ (Applied Biosystems, Life Technologies, USA) using the comparative $\Delta \mathrm{Ct}$ method. Each reaction was conducted with a volume of $10 \mu \mathrm{L}$ using the Maxima ${ }^{\circledR}$ SYBR Green/ROX qPCR Master Mix (Thermo Scientific, USA). The amplification conditions were as follows: $95^{\circ} \mathrm{C}$ for $10 \mathrm{~min}, 40$ cycles at $95^{\circ} \mathrm{C}$ for $30 \mathrm{~s}, 60^{\circ} \mathrm{C}$ for $30 \mathrm{~s}$, and $72^{\circ} \mathrm{C}$ for $30 \mathrm{~s}$. Beta-tubulin was selected as the housekeeping gene (HKG) due to its stable value as inferred through the NormFinder algorithm. The other HKGs tested were alpha-tubulin, elongation factor alpha, and beta-actin. Statistical analyses were performed using the software Statistical 8.0. The data obtained were analyzed through the Kruskal-Wallis test with the Statistica software (Version 7.0, StatSoft, Inc.). Statistically significant differences were accepted with a $\mathrm{p}<0.05$.

\section{Results}

\section{Molecular characterization of $\mathrm{Cr}$-P-glycoprotein}

The sequence for the characterized Pgp gene was obtained by assembling partial sequences identified in the Illumina cDNA library for $C$. rogercresseyi and the fragment amplified by RACE-PCR. The full

A

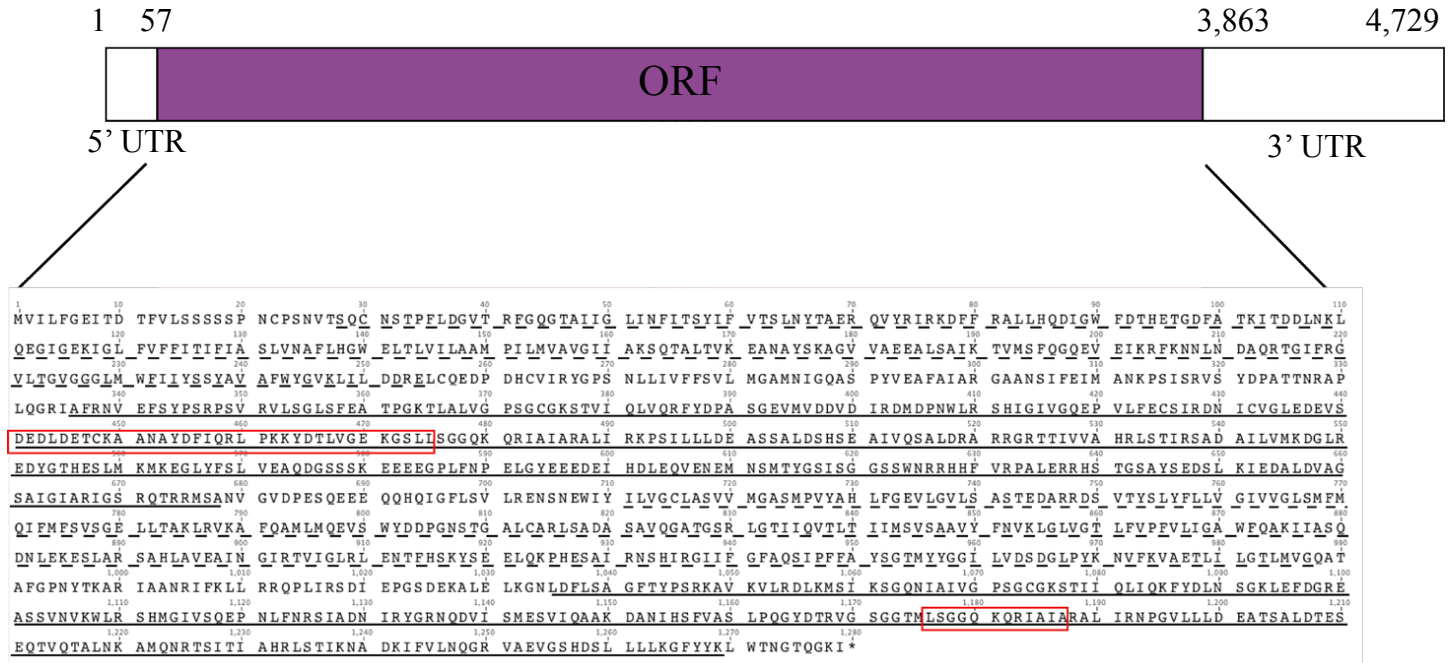

B

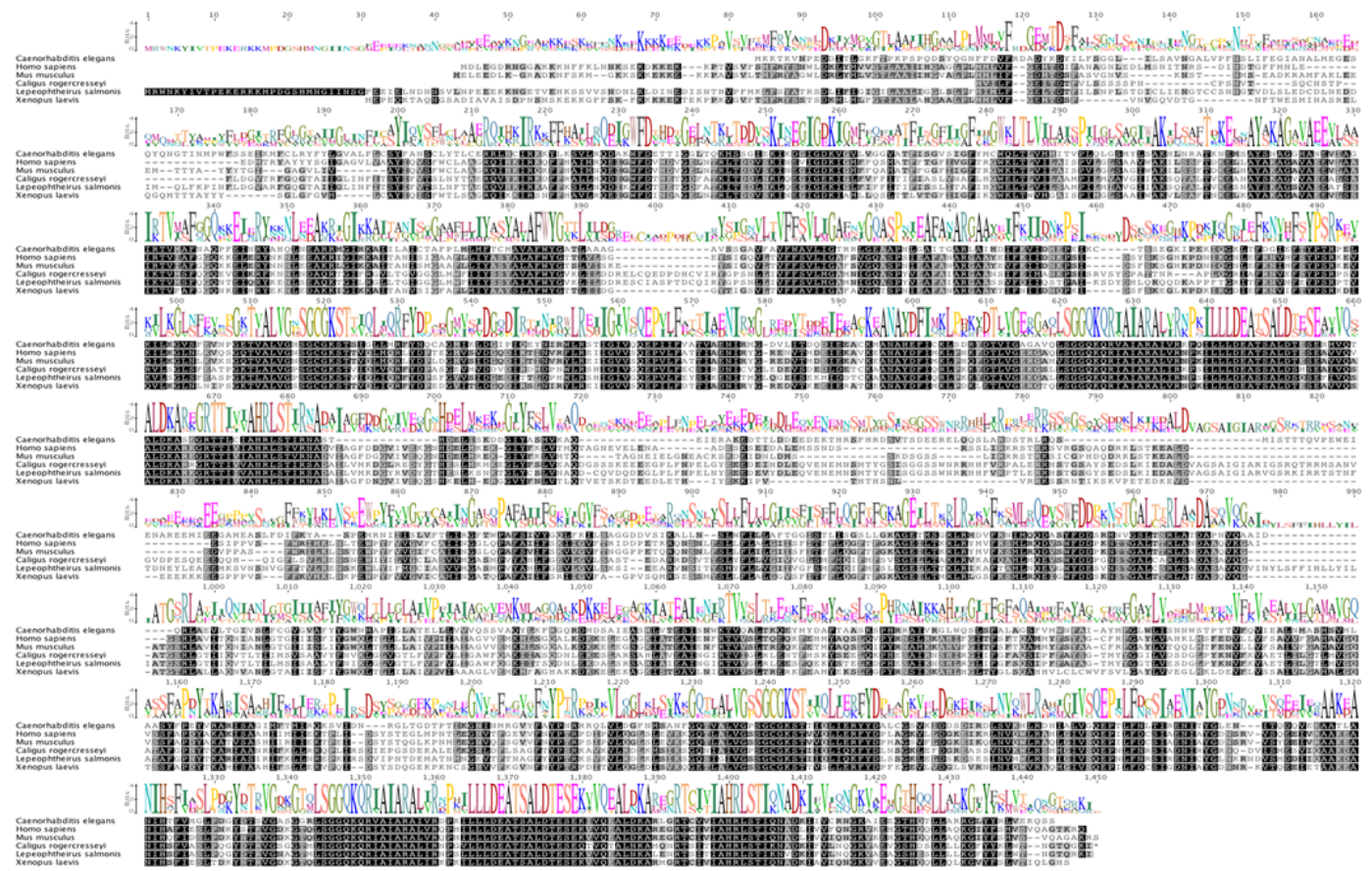

Figure 1: Cr-Pgp molecular characterization. (A) Full-length cDNA sequence and predicted amino acid sequence for Cr-Pgp (GenBank access $\left.n^{\circ} \mathrm{KF} 704367\right)$. Transmembrane domain in discontinuous underline; Nucleotide binding domain in underlined; ABC transporter signature motif in red box. (B) Multiple alignment of Cr-Pgp, in black the conserved amino acid residues. 
sequence for the Cr-Pgp gene was deposited into the NCBI Genbank database under GenBank Accession No. KF704367. The complete cDNA sequence for Cr-Pgp had 4,730 bp with an open reading frame (ORF) of 3,840 bp encoding for 1,280 amino acids, while the 5'UTR was $56 \mathrm{bp}$ and the 3'UTR was $833 \mathrm{bp}$ (Figure 1A). The amino acid sequence had a predicted molecular weight of $140.3 \mathrm{kDa}$ and an isoelectric point of 6.07. ABC transporters minimally consist of two conserved regions: a highly conserved ATP binding cassette (ABC) and a less conserved transmembrane domain (TMD). These can be found on the same protein or on two different ones. Herein, the translation of the $C r$-Pgp cDNA sequence detected ABC-transporter transmembrane domains (TMDs) and nucleotide binding domains (NBD), arranged in an N-terminal to C-terminal order of TMD-NBD-TMD-NBD, the typical domain architecture of $\mathrm{ABC}$ full transporters (Figure 1A). Further, two TMDs with six transmembrane helices each, and two cytosolic domains were predicted.

From a multiple sequence alignment of $C r-P g p$, a $75.7 \%$ identity was observed with sequences described for Lepeophtheirus salmonis and a $43.3 \%$ identity was observed with the homologues sequences described for Homo sapiens and Drosophila menalogaster (Figure 1B). After performing a phylogenetic analysis through the neighbor-joining method, two clades were observed, one of these being for vertebrates and the other for invertebrate species. The Cr-Pgp sequence was grouped, as expected, within the sequences of $C r$-Pgp reported for $L$. salmonis (Figure 2).

\section{Expression analysis}

To determine the effect of deltamethrin over Cr-Pgp expression we evaluated individuals obtained from bioassays and compared with a gene involved in detoxification process as P450. From the qPCR analysis higher expression levels of $\mathrm{Cr}-\mathrm{Pgp}$ and $\mathrm{Cr}$-P450 were observed in samples exposed to $2 \mathrm{ppb}$ of deltamethrin (Figure 3). Furthermore, Cr-Pgp in female shows higher transcription levels

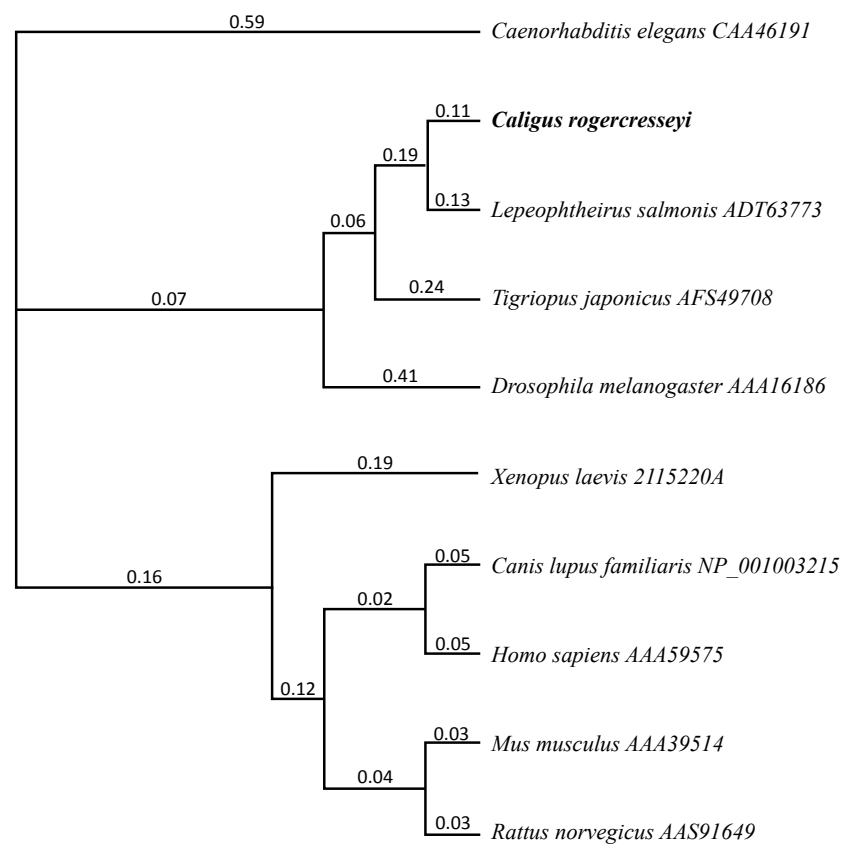

Figure 2: Phylogenetic analysis of Cr-Pgp with vertebrate and invertebrate P-gp orthologous. The phylogenetic tree was constructed using the full amino acid sequences with MUSCLE software and 1000 bootstrap repetitions.

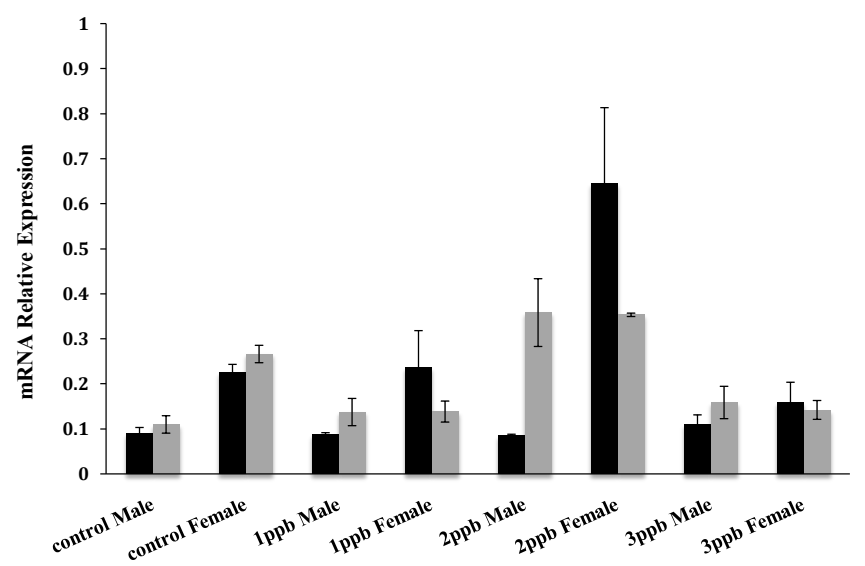

Figure 3: Relative expression level of $\mathrm{Cr}$-Pgp and comparison with $\mathrm{Cr}$-P450 in adults exposed to deltamethrin. Black bar: $C r$-P-gpgene expression, Grey bar: P450 gene expression. All data have significantly differences $(p<0.05)$.

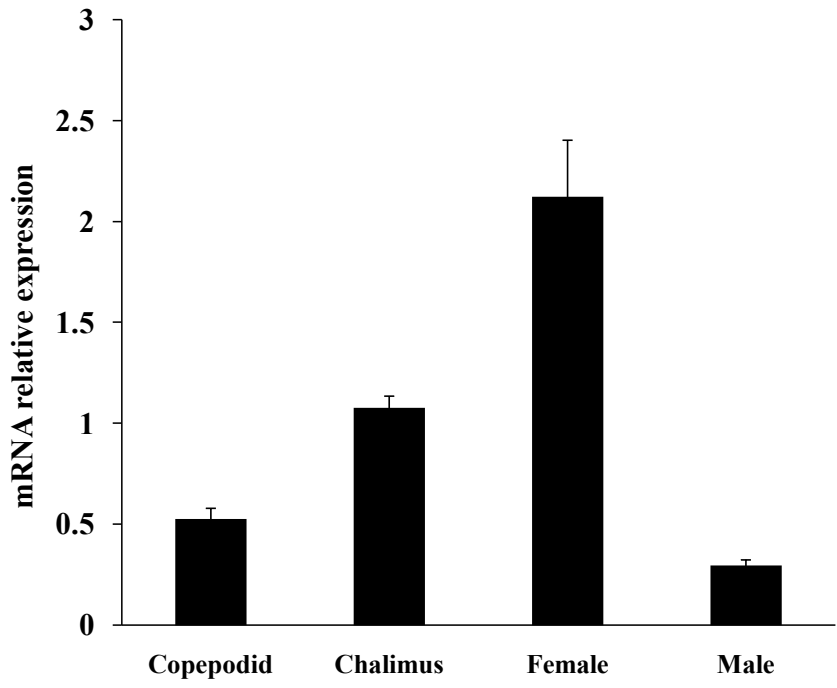

Figure 4: Relative expression level of Cr-Pgp in different developmental stages. Each bar represents the mean normalized expression levels of replicates $(\mathrm{N}=3)$. All data have significantly differences $(\mathrm{p}<0.05)$.

\begin{tabular}{|c|c|c|}
\hline Deltamethrin (ppb) & Female & Male \\
\hline 0 & 100 & 100 \\
\hline 1 & 53,3 & 13,3 \\
\hline 2 & 26,7 & 20,0 \\
\hline 3 & 26,7 & 0,0 \\
\hline
\end{tabular}

Table 2: Percentage of survival of sea louse exposed to deltamethrin.

than males, which is reflected in the higher percentage of survival in female individuals (Table 2). Contrary, $\mathrm{Cr}$-P450 not significant differences in gene expression between male and female samples were observed (Figure 3). Through qPCR, the transcript levels for the characterized gene were analyzed in different stages of development copepodid, chalimus, and male and female adults. Relative expression calculated using housekeeping gene beta-tubulin presented a stability value as calculated by the NormFinder algorithm. Comparing the four samples, the highest expression levels of $C r$-Pgp were observed in adult females, and an overregulation was registered for adult males (Figure 4). Comparing the copepodid and chalimus stages, an up-regulation 


\begin{tabular}{|l|l|l|l|}
\hline Position & Variation & Frequency & Substitution \\
\hline 1091 & G/A & 27,27 & synonymous \\
\hline 1121 & C/T & 26,97 & synonymous \\
\hline 1196 & C/T & 47,22 & synonymous \\
\hline 1266 & A/T & 36,84 & nonsynonymous \\
\hline 1353 & G/A & 33,8 & nonsynonymous \\
\hline 1415 & G/A & 28,57 & synonymous \\
\hline 2603 & C/T & 43,75 & synonymous \\
\hline 2666 & C/G & 42,99 & synonymous \\
\hline 2933 & G/A & 30 & synonymous \\
\hline 3458 & G/A & 36,51 & synonymous \\
\hline
\end{tabular}

Table 3: SNPs variation identified in Cr-Pgp sequence.
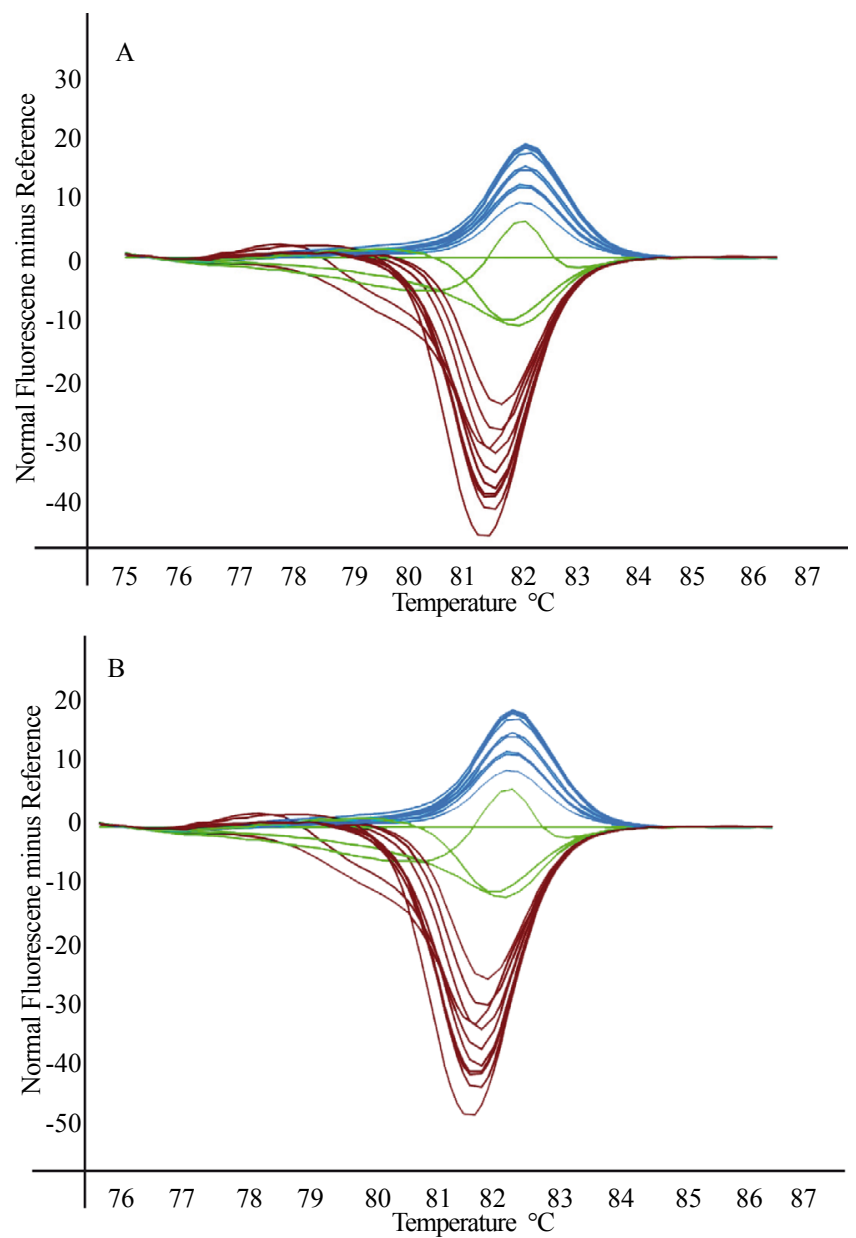

Figure 5: High Resolution Melting curves. A: difference curve for visual identification of allele $A / T$ position 1,266; B: difference curve for visual identification of allele G/A position 1,353.

was observed in chalimus samples. The expression analysis showed that $C r-P g p$ it was strongly regulated in females, suggesting a better detoxification mechanism to pyrethroid.

\section{SNPs identification and validation}

From the characterization of nucleotide sequence, a total of eleven SNPs present in the ORF of Cr-Pgp obtained from 10,921 reads were identified. Two SNPs located at $+1,266 \mathrm{~A} / \mathrm{T}$ and $+1,353 \mathrm{G} / \mathrm{A}$ were nonsynonymous and involved in amino acid changes between Met/ Leu and Val/Ile (Table 3). Furthermore, 20 adults of $C$. rogercresseyi were genotyped by HRMA analysis and showed three profiles of melt curves, evidencing the different allelic variants for these SNPs (Figure 5). However, it is necessary evaluates the SNPs in groups with different susceptibility to pyrethroids in order to associate putative mutations with resistance to xenobiotics.

\section{Discussion}

$\mathrm{ABC}$ transporters are transmembrane proteins responsible for the translocation of various compounds in prokaryotic and eukaryotic organisms [8]. In mammals and fish, proteins belonging to this family have a role in the metabolism of xenobiotics [8]. In bivalves which are constantly exposed to toxins, the proteins of this family have been observed to act as a protection barrier against xenobiotics in the gills, thus restricting the transport of toxic substances to other tissues [34]. One member of this family is the P-glycorpotein, which is a highly conserved protein in vertebrate and invertebrate organisms and which is formed by two nucleotide-binding domains (NBD) and two transmembrane (TMB) domains. Moreover, Pgp has two drug binding sites which act as a substrate and which restrict the quantity of drugs incorporated into the cells through ATPasa activity [35]. One of the substrates with the greatest affinity for Pgp are the avermectins, which are used for controlling parasites, among which are nematodes and copepods, by acting as a barrier to the nervous system $[3,4,36]$.

The overuse of xenobiotics for controlling infestations of salmon lice without an adequate control and management system has generated an increased resistance in natural populations. This study characterized the full cDNA of $P$-glycoprotein in C. rogercresseyi, evidencing a coding sequence of 1,280 amino acids that contain two highly conserved TMB and NBD domains $[8,35,36]$. The phylogenetic analysis showed that $\mathrm{Cr}$ $P g p$ had an identity of $76.7 \%$ with its homologue describe in L. salmonis [24] and $77.6 \%$ of identity with SL-PGY1 describe by Heumann [17]. Moreover, this gene showed a high homology with sequences described for Homo sapiens and Drosophila melanogaster, confirming Cr-Pgp as a member belonging to the $\mathrm{ABC}$ transporter family.

In cell lines of mammals, the accumulation of xenobiotic agents has been observed to increase chemical resistance, which is associated with changes in the expression of $P g p$ [6]. As observed in nematodes treated with avermectins, $P g p$ increased its transcripts levels and conferred resistance, making treatment with avermectins an inefficient method [3,7]. In L. Salmonis [17,25] and C. rogercresseyi [21], adult copepods exposed to EMB evidences an increase of their Pgp transcriptional activity that in turn affect the efficiency of EMB as chemical antiparasite.

The metabolism of pyrethroids in many species has been associated to overexpression of cytochrome enzyme P450 [36-38]. In Helicoverpa armigera at least five CYP genes that encode a P450 enzyme were overexpressed in a resistance strain, suggesting that multiple $\mathrm{P} 450$ enzymes are involved in deltamethrin resistance [19]. Besides, an increased sensibility to deltamethrin was observed in $L$. salmonis after pre-treatment with piperonyl butoxide (PBO), which is a $\mathrm{P} 450$ inhibitor, suggesting the role of these enzyme to pyrethroid metabolism in copepods [39]. Bariami et al. [12] in Aedes aegypti identified twenty genes from the P450 superfamily which were overexpressed in resistant strains, also the authors observed an increased level of transcripts of $\mathrm{ABC}$ transporter gene, which is orthologous to $A B C B 4$ describe for Anopheles gambiae [39]. These results indicate that $\mathrm{ABC}$ transport proteins could be involved in pyrethroid detoxification process. Our results evidenced an overexpression of $C r$-Pgp and $P 450$ genes in sea louse exposed to $2 \mathrm{ppb}$ of deltamethrin, suggesting a relation between both genes and a potential resistance to pyrethroid in C. rogercresseyi. 
Citation: Valenzuela-Muñoz V, Nuñez-Acuña G, Gallardo-Escárate C (2014) Molecular Characterization and Transcription Analysis of $P$-Glycoprotein Gene from the Salmon Louse Caligus rogercresseyi. J Aquac Res Development 5: 236 doi:10.4172/2155-9546.1000236

Page 6 of 7

However, these results are different to some previous investigations. In several studies in mouse cell lines, between Pgp and various pesticides demonstrate a low interaction among pyrethroids and Pgp protein [40]. Furthermore, in the parasite Rhipocephalus microplus exposed to ABC transporter inhibitors was observed higher mortality in individuals treated with iveromectin (averomectin), but not in parasites treated with cypermethrin (pyrethroid) [41]. This could indicate an absence of pyrethroid efflux mediated by Pgp in these studied species.

Studies of xenobiotic resistance in salmon lice and the evaluation of Pgp expression has only been carried out in adult individuals exposed to EMB, showing a difference in expression levels between males and females [19]. Analysis from the current study shows that female specimens of $C$. rogercresseyi presented higher levels of Pgp than males, which is contrary to the information reported for $L$. salmonis. Additionally, Igboeli [18] observed that the increased expression of PgP observed in males occurred at an earlier stage than in females, granting males a greater resistance to EMB. From this, it is possible to predict that the greater expression of Pgp observed in females of C. rogercresseyi in the current study could be linked to a greater resistance. This is consistent with the results obtained from $\mathrm{Cr}$-Pgp expression in samples exposed to deltamethrin, where females present higher expression levels in relation to males. In regards to Pgp expression, there are no reports for the earliest developmental stages. It is known that when copepodids are exposed to EMB, development is interrupted, and in the chalimus stage, maturation is delayed [22]. Through expression analysis, it is inferred that copepodids of the analyzed population would be more susceptible to EMB given that the expression $\mathrm{Cr}-\mathrm{Pgp}$ transcripts in this stage were lower than in the chalimus stage and adult females of $C$. rogercresseyi. An overregulation of chalimus Cr-Pgp was observed in comparison with expression in copepodids and males, whose expression patterns were similar to those observed in pre-adults and female adults of L. salmonis [19].

The expression and functionality of Pgp could be influenced by the presence of molecular polymorphisms, for instance SNPs within the sequence, which could cause differences in the efficiency of the xenobiotic in different individuals $[42,43]$ evaluated the response of $P g p$ in humans to changes caused by a SNP $(\mathrm{C} / \mathrm{T})$ located in position 3,435 , which did not alter the protein but showed an overexpression of the gene in homozygote individuals [42]. In females of Onchocerca volvulus, three SNPs were identified which affected the functionality of Pgp [43]. In reference to the characterization of SL-PGY1 in $L$. salmonis, no SNPs were reported [17]. However, this study reports 11 SNPs mutations as validated through HRMA. Two of these generated nonsynonymous changes in Met/Leu and Val/Ile. Future studies will evaluate the association of these polymorphisms with resistance or susceptibility to chemotherapeutic agents in the salmon louse $C$. rogercresseyi $[44,45]$

The present study is the first to describe the mRNA of P-glycoprotein for $C$. rogercresseyi and simultaneously to measure its expression in adults expose to pyrethroid, and during the larval and adult stages of $C$. rogercresseyi. The results showed a relation between $\mathrm{Cr}-\mathrm{Pgp}$ expression and the detoxifying gene $C r-P 540$, suggesting a role of $C r-P g p$ in pyrethroid metabolism.

\section{Acknowledgment}

This study was funded by grant provided by CONICYT-Chile, FONDAP project 15110027.

\section{References}

1. Lauritano C, Procaccini G, lanora A (2012) Gene Expression Patterns and
Stress Response in Marine Copepods. Marine Environmental Research 76 22-31

2. Pohl P, Klafke G, Júnior JR, Martins JR, Silva Vaz I, et al. (2012a) ABC Transporters as a Multidrug Detoxification Mechanism in Rhipicephalus (Boophilus) Microplus. Parasitol Res 111: 2345-2351.

3. James CE, Davey MW (2009) Increased Expression of ABC Transport Proteins is Associated with Ivermectin Resistance in the Model Nematode Caenorhabditis Elegans. Int J Parasitol 39: 213-220.

4. Yan R, Urdaneta-Marquez L, Keller K, James CE, Davey MW, et al. (2012) The Role of Several ABC Transporter Genes in Ivermectin Resistance in Caenorhabditis Elegans. Vet Parasit 190: 519-529.

5. Juranka PF, Zastawny RL Ling V (1989) P-Glycoprotein: Multidrug-Resistance and a Superfamily of Membrane-Associated Transport Proteins. FASEB J 3 : 2583-2592.

6. Pouliot Jfß, L'Heureux Fß, Liu Z, Prichard RK, Georges E (1997) Reversa of P-Glycoprotein-Associated Multidrug Resistance by Ivermectin. Biochem Pharmacol 53: 17-25.

7. Xu M, Molento M, Blackhall W, Ribeiro P, Beech R, et al. (1998) Ivermectin Resistance in Nematodes May Be Caused by Alteration of P-Glycoprotein Homolog. Mol Biochem Parasitol 91: 327-335.

8. Hung LW, Wang IX, Nikaido K, Liu PQ, Ames GFL, et al. (1998) Crystal Structure of the ATP-Binding Subunit of an ABC Transporter. Nature 396: 703707.

9. Boxshall GA, Bravo S (2000) On the Identity of the Common Caligus (Copepoda: Siphonostomatoida: caligidae) From Salmonid Netpen Systems in Southern Chile. Contributions to Zoology 69: 137-146.

10. Gonzalez L, Carvajal J (2003) Life Cycle of Caligus Rogercresseyi, (Copepoda: Caligidae) Parasite of Chilean Reared Salmonids. Aquaculture 220: 101-117.

11. Sevatdal S, Horsberg TE (2003) Determination of Reduced Sensitivity in Sea Lice (Lepeophtheirus Salmonis, Kroyer) Against the Pyrethroid Deltamethrin Using Bioassays and Probit Modelling. Aquaculture 218: 21-31.

12. Bariami V, Jones CM, Poupardin R, Vontas J, Ranson H (2012) Gene Amplification, ABC Transporters and Cytochrome P450s: Unraveling the Molecular Basis of Pyrethroid Resistance in the Dengue Vector, Aedes aegypti. Plos Negl Trop Dis 6: E1692.

13. Black KD, Fleming S, Nickell TD, Pereira PM (1997) The Effects of Ivermectin Used to Control Sea Lice on Caged Farmed Salmonids, on Infauna Polychaetes. ICES Journal of Marine Science: Journal Du Conseil 54: 276-279.

14. Carmichael SN, Bron JE, Taggart JB, Ireland JH, Bekaert MI, et al. (2013) Salmon Lice (Lepeophtheirus Salmonis) Showing Varying Emamectin Benzoate Susceptibilities Differ In Neuronal Acetylcholine Receptor and GABA-Gated Chloride Channel Mrna Expression. BMC Genomics 14: 408.

15. Ffrenche-Constant RH, Daborn, PJ, Goff GL (2004) The Genetics and Genomics of Insecticide Resistance. Trends in Genetics 20: 163-170.

16. Walsh TK, Lyndon AR, Jamieson DJ (2007) Identification of Cdnas Induced by the Organophosphate Trichlorphon in the Parasitic Copepod Lepeophtheirus Salmonis Copepoda; Caligidae). Pesticide Biochemistry and Physiology 88 26-30.

17. Heumann J, Carmichael S, Bron JE, Tildesley A, Sturm A (2012) Molecula Cloning and Characterisation of a Novel P-Glycoprotein in the Salmon Louse Lepeophtheirus Salmonis. Comp Biochem Physiol C: Toxicol Pharmacol 155: 198-205.

18. Igboeli O, Purcell S, Wotton H, Poley J, Burka J, et al. (2012) Immunostimulation of Salmo Salar L., and Its Effect on Lepeophtheirus Salmonis (Kroyer) P-Glycoprotein Mrna Expression Following Subsequent Emamectin Benzoate Exposure. J Fish Dis 36: 339-351.

19. Igboeli OO, Burka JF, Fast MD (2013) Sea Lice Population and Sex Differences in P-Glycoprotein Expression and Emamectin Benzoate Resistance on Salmon Farms in the Bay of Fundy, New Brunswick, Canada. Pest Manag Sci 70: 905914.

20. Bravo S, Treasurer J, Sepulveda M, Lagos C (2010) Effectiveness of Hydrogen Peroxide in the Control of Caligus rogercresseyi in Chile and Implications for Sea Louse Management. Aquaculture 303: 22-27.

21. Cárcamo JG, Aguilar MN, Barrientos CA, Carreñoo CF, Quezada CA, et al. (2011) Effect of Emamectin Benzoate on Transcriptional Expression 
Citation: Valenzuela-Muñoz V, Nuñez-Acuña G, Gallardo-Escárate C (2014) Molecular Characterization and Transcription Analysis of $P$-Glycoprotein Gene from the Salmon Louse Caligus rogercresseyi. J Aquac Res Development 5: 236 doi:10.4172/2155-9546.1000236

of Cytochromes P450 and the Multidrug Transporters (Pgp And MRP1) in Rainbow Trout Oncorhynchus Mykiss and the Sea Lice Caligus Rogercresseyi. Aquaculture 321: 207-215.

22. Stone J, Sutherland I, Sommerville C, Richards R, Endris R (2000) The Duration of Efficacy Following Oral Treatment with Emamectin Benzoate Against Infestations of Sea Lice, (Kroyer), In Atlantic Salmon Salmo Salar L. J Fish Dis 23: 185-192.

23. Lees F, Baillie M, Gettinby G, Revie CW (2008) The Efficacy of Emamectin Benzoate Against Infestations of Lepeophtheirus Salmonis on Farmed Atlantic Salmon Salmo Salar In Scotland, 2002, Äi2006. Plos One 3: E1549.

24. Tribble ND, Burka, JF, Kibenge FSB (2007a) Evidence for Changes in the Transcription Levels of Two Putative P-Glycoprotein Genes in Sea Lice (Lepeophtheirus Salmonis) in Response to Emamectin Benzoate Exposure. Mol Biochem Parasitol 153: 59-65.

25. Tribble ND, Burka, JF, Kibenge FSB (2007b) Identification of the Genes Encoding For Putative Gamma Aminobutyric Acid (GABA) and GlutamateGated Chloride Channel (Glucl) Alpha Receptor Subunits In Sea Lice (Lepeophtheirus Salmonis). J Vet Pharmacol Ther 30: 163-167.

26. Burridge L, Weis JS, Cabello F, Pizarro J, Bostick K (2010) Chemical Use in Salmon Aquaculture: A Review of Current Practices and Possible Environmental Effects. Aquaculture 306: 7-23.

27. Brun-Barale A, Héma O, Martin T, Suraporn S, Audant P, et al. (2010) Multiple P450 Genes Overexpressed in Deltamethrin-Resistant Strains of Helicoverpa Armigera. Pest Manag Sci 66: 900-909.

28. Buss DS, Mccaffery AR, Callaghan A (2002) Evidence for P-Glycoprotein Modification of Insecticide Toxicity in Mosquitoes of the Culex Pipiens Complex. Med Vet Entomol 16: 218-222.

29. Stevenson BJ, Bibby J, Pignatelli P, Muangnoicharoen SO, Äôneill PM, et al (2011) Cytochrome P450 6M2 From the Malaria Vector Anopheles Gambiae Metabolizes Pyrethroids: Sequential Metabolism of Deltamethrin Revealed. Insect Biochem Mol Biol 41: 492-502.

30. Arriagada GA, Stryhn H, Campistó L, Rees E, Sanchez J, et al. (2014) Evaluation of the Performance of Pyrethroids on Different Life Stages of Caligus Rogercresseyi in Southern Chile. Aquaculture 426-427.

31. Drummond A (2009) Geneious. 5.1 Available From:Http://Www.Geneious Com.

32. http://www.expasy.org/

33. http://smart.embl-heidelberg.de/
34. Luckenbach T, Epel D (2008) ABCB-And ABCC-Type Transporters Confer Multixenobiotic Resistance and Form an Environment-Tissue Barrier In Bivalve Gills. Am J Physiol Regul Integr Comp Physiol 294: R1919-R1929.

35. Aller SG, Yu J, Ward A, Weng Y, Chittaboina S, et al. (2009) Structure of P-Glycoprotein Reveals a Molecular Basis for Poly-Specific Drug Binding Science 323: 1718-1722.

36. Kim RB, Fromm MF, Wandel C, Leake B, Wood A, et al. (1998) The Drug Transporter P-Glycoprotein Limits Oral Absorption and Brain Entry of HIV-1 Protease Inhibitors. J Clin Invest 101: 289-294.

37. Shen B, Dong HQ, Tian HS, Ma L, Li XL, et al. (2003) Cytochrome P450 Genes Expressed in The Deltamethrin-Susceptible and-Resistant Strains of Culex Pipiens Pallens. Pesticide Biochemistry and Physiology 75: 19-26.

38. Wheelock GD, Scott JG (1992) The Role of Cytochrome P450Ipr in Deltamethrin Metabolism by Pyrethroid-Resistant and Susceptible Strains of House Flies. Pesticide Biochemistry and Physiology 43: 67-77.

39. Sevatdal S, Fallang A, Ingebrigtsen K, Horsberg TE (2005) Monooxygenase Mediated Pyrethroid Detoxification in Sea Lice (Lepeophtheirus Salmonis). Pest Manag Sci 61: 772-778.

40. Bain LJ, Leblanc GA (1996) Interaction of Structurally Diverse Pesticides with the Human MDR1 Gene Product P-Glycoprotein. Toxicol Appl Pharmacol 141 288-298.

41. Pohl P, Klafke G, Junior JR, Martins Jo, Silva Vaz I, et al. (2012b) ABC Transporters As A Multidrug Detoxification Mechanism In Rhipicephalus (Boophilus) Microplus. Parasitol Res 111: 2345-2351.

42. Ishikawa T, Hirano H, Onichi Y, Sakura A, Tauri S (2004) Functional Evaluation of ABCB1 (P-Glycoprotein) Polymorphisms: High-Speed Screening and Structure-Activity Relationship Analyses. Drug Metab Pharmacokinet 19: 1-14.

43. Bourguinat C, Ardelli BF, Pion Sbds, Kamgno J, Gardon J, et al. (2008) P-Glycoprotein-Like Protein, A Possible Genetic Marker for Ivermectin Resistance Selection in Onchocerca volvulus. Mol Biochem Parasitol 158: 101 111.

44. Jones M, Sommerville C, Wootten R (1992) Reduced Sensitivity of the Salmon Louse, Lepeophtheirus Salmonis, To the Organophosphate Dichlorvos. J Fish Dis 15: 197-202.

45. Jones PG, Hammell KL, Gettinby G, Revie CW (2013) Detection of Emamectin Benzoate Tolerance Emergence In Different Life Stages of Sea Lice, Lepeophtheirus Salmonis, on Farmed Atlantic Salmon, Salmo Salar L. J Fish Dis 36: $209-220$. 